\title{
Research on Marketing Strategy Innovation of Enterprise in Mobile Internet
}

\author{
Xiuping Liu ${ }^{1}$ \\ ${ }^{1}$ Nanchang Institute of Science \& Technology, Nanchang, Jiangxi, 330000
}

Keywords: marketing strategy; enterprise management; mobile Internet

\begin{abstract}
The rapid development of the Internet has brought more opportunities for business marketing and made corporate marketing activities more efficient. Faced with the opportunities at the same time, the traditional enterprise marketing is also facing challenges, and the traditional marketing methods and means need reform and innovation. This paper analyzes the difference between the era of mobile Internet and the traditional era of marketing, and puts forward the strategies and means of transformation of marketing strategy in the era of mobile Internet, in order to provide some help to the enterprise.
\end{abstract}

\section{Introduction}

With economic development, good products do not mean good business. Internet thinking has begun to take the place of industrial thinking. Enterprises need to re-examine their core values and enhance the competitiveness of the value chain through a series of reforms. The era of mobile Internet, business business model is undergoing earth-shaking changes. People's working life is full of wireless network, wifi, hotspot, 3G / 4G network, the use of mobile phones, tablet PCs and other handheld terminals can carry out network activities. People use the fragmented time browsing mobile application APP at any time, to complete the friends, learning and shopping and other activities [1]. Traditional enterprises rely on the experience of the existence of the environment has disappeared, how to continue profitability, which requires businesses to change business thinking, using one of the variables leverage - marketing. In the era of mobile Internet, traditional enterprises are not eliminated by Internet companies, but traditional business models are replaced by new business models. In essence, is the mobile Internet platform to re-create the traditional channels. Therefore, enterprises should carry out marketing strategy transformation, make full use of network technology, effectively carry out marketing activities.

\section{Definition and Characteristics of Marketing in Mobile Internet}

There are many domestic researches on mobile Internet marketing, but there is still no consensus on the definition of mobile Internet marketing. Baidupedia points out that mobile Internet marketing is based on MMS, QR code, WAP, mobile phone applications and mobile Internet technologies This type of marketing has the characteristics of strong flexibility, high precision and strong interaction. MBA MBA Encyclopedia points out that mobile Internet marketing refers to the combination of mobile communication devices such as mobile phones, PDAs, laptops and wireless Internet technologies Constitute an Internet marketing system, and provide a full range of standard one-stop business mobile business services, a new marketing strategy; Dr. Xu Shuhua Beijing University of Posts and Telecommunications that mobile Internet marketing refers to the mobile terminal (mobile phones, tablet PCs, etc.) users, In the mobile terminal using mobile communications equipment and wireless Internet technology to form an Internet marketing system directly to the target audience targeted and accurate delivery of personalized instant messaging through consumer information interaction to achieve a marketing goal of a behavior. Because mobile Internet technology can better collect the user's behavior characteristics, preferences, geographical location and other information, therefore, mobile Internet marketing can be better, more accurate and more targeted to SMEs product information and services to push it High degree of matching target user groups. Such as location based service (LBS), Location Based Service, businesses can use this technology to easily 
find the target customers around, its marketing activities or advertising precision push, consumers can also use this technology to quickly search businesses, Find the products and services that match their needs. In the era of mobile Internet, people can make use of all kinds of fragmentary time to do shopping, entertainment, product information and news watching in their daily working life, for example, one minute, one half and a half, the mobile Internet effectively makes up The time gap caused by the fragmentation of time. It is precisely because people use mobile devices no longer subject to the scene, time and other restrictions, making SMEs and consumers to enhance communication between the interaction more timely and conducive to SMEs to achieve more effective communication effect [3]. With the continuous update of new mobile Internet technologies, mobile Internet marketing model is also more and more innovative and diversified, such as game interaction, set praise and other marketing models, on the one hand because of consumer marketing activities put forward higher requirements, consumption Who are more willing to accept the information of SMEs' products and services in entertainment and learning, but do not want to passively and unilaterally disseminate and accept it. On the other hand, due to the popularization of social media and the change of people's consumption awareness, SMEs have to change Past marketing model. The marketing cost here refers mainly to the material cost. Everyone in the era of mobile Internet is a communication center, which provides a low-cost channel for communication. In the traditional Internet era, SMEs need to spend huge amounts of money to promote their products and services information, the effect is not necessarily ideal, but in the mobile Internet era, as long as SME marketing content is creative, Internet users think it is valuable or interesting, it will help businesses Free fission spread.

\section{Green Marketing Strategy in Enterprises in Mobile Internet}

In the era of mobile Internet, to establish a green marketing concept is the corporate identity of the corporate identity recognition system identification, what kind of concept will show what kind of action, and the concept of green marketing to the enterprise of each employee's The heart, that is, shaping the corporate culture of green values. Enterprises in the decision-making time to think whether to meet the green requirements, whether in line with the concept of green development. This also requires entrepreneurs to have a green marketing perspective. By actively promoting green marketing from top to bottom and from bottom to top, businesses also ensure the implementation of green culture on a systematic basis. In the overall corporate strategy to reflect the embodiment of green marketing, from a long-term perspective, the green marketing as the goal of business development. Through behavioral identification and visual identification, the corporate green image can be fully established. Through the mobile Internet to spread the corporate philosophy of green, through education and learning activities dedicated to shaping the corporate green values.

The green product strategy in this article refers broadly to follow the green principle in the formulation of product strategy, not just the green certified product. How to reduce resource consumption and how to reduce waste are the problems to be solved in green marketing. How to reduce the waste of resources, such as the emergence of mobile Internet, To a certain extent, this reduces the waste of resources. For example, books, we used to read the book to the bookstore or through the Internet to buy books on the computer, and now the emergence of the mobile Internet, e-books with its convenience to read anytime, anywhere and more affordable prices by many readers of all ages. Green brand strategy, in the design of products, consider its energy saving requirements, such as the automotive industry hybrid and new energy vehicles. Green packaging strategy, packaging strategy in the era of mobile Internet embodied in many aspects, especially the over-packaging courier issues, the emergence of mobile Internet makes it easier to buy goods online, therefore, express packaging is also a problem to be solved, do To green packaging, one to reduce unnecessary packaging; the second is the use of packaging materials, as far as possible the use of biodegradable packaging materials; third is to promote the reuse of packaging, through effective means to encourage consumers and related businesses to actively reuse package.

In the process of green marketing, green product design may increase the cost of products and 
services, which requires enterprises to conduct appropriate surveys to understand the consumer's psychological expectations of green products, price acceptance, combined with the relevant national policies, let people benefit, develop a reasonable green price strategy. Channel strategy involves relationship marketing, and the relevant intermediaries to reach an agreement to jointly safeguard the green image, while minimizing the channel links and reduce the channel waste of resources, in the enterprise channel logistics links among green vehicles to do the application of green Establishment of distribution center. The advent of the Internet makes the traditional channels have a greater impact, the emergence of mobile Internet, making people shop in the physical store to further reduce the time, which in part also makes the business cost is reduced, but also a green marketing channel. Green marketing strategy, on the one hand the choice of promotional tools, so that green energy. From the perspective of the application of the promotion combination, reducing the input of paper advertisements and replacing the application of paper advertisement by mobile Internet, the specific tactics include mobile advertisement, promotion through QR code, Weibo, WeChat and APP etc. Public number, through event marketing, content marketing, word of mouth marketing and other promotional promotional activities and promotion. On the other hand, in the promotion process, pay attention to the promotion of green image, through the application of overall marketing tools to establish a green corporate image [4].

In addition to meeting the needs and desires of consumers, enterprises should also make efforts to promote green consumption behavior of consumers by advocating consumers to purchase green products through corporate promotion and promotion, and encouraging consumers to generate green consumption through corporate strategy formulation behavior. Under the guidance of the overall national strategy, through the joint efforts of enterprises, consumers and relevant departments, the green development pattern of the whole society should be constructed.

In order to better use of mobile Internet marketing, SMEs need to deepen the study, understanding and cognition of mobile Internet marketing connotation, theory, methods and other knowledge. The government should address the popularization and education of SMEs on mobile Internet marketing related knowledge and increase the support for mobile Internet marketing training for SMEs to attract more SMEs to participate in the mobile Internet marketing camp; SMEs themselves should be proactive to participate in government organized some mobile Internet marketing conferences, forums, training and other activities. SMEs in the mobile Internet marketing to go farther [5], it is necessary to strengthen the building of qualified personnel, colleges and universities is the place to transfer talent, so SMEs can jointly train mobile Internet marketing talents with universities, the two establish a relative Stable relations of cooperation. On the one hand, colleges and universities can add information on SMEs' products and services to relevant courses in network marketing to enable students to understand the situation and business of SMEs while they are in school; on the other hand, enterprises can select key staff to teach classes in schools Master the theory to practice. This model of joint training of personnel on the one hand exercise of students' ability to practice mobile Internet marketing, improve the quality of personnel training in colleges and universities.

\section{Conclusion}

With the rapid development of mobile Internet, more and more small and medium-sized enterprises begin to touch mobile Internet marketing. Based on expatiating on the connotation and characteristics of mobile internet marketing, this paper analyzes the forms and existing problems of mobile internet marketing and puts forward some countermeasures to innovate the internet marketing strategy for SMEs in the era of mobile internet: to strengthen the cognition of mobile Internet marketing and to jointly train mobile internet Marketing personnel, according to consumer demand for personalized precision marketing.

\section{References}

[1] Xu Shuhua, Wang Jiao. Mobile marketing and marketing model of the development process [J]. 
Mobile Communications, 2011 (23): 60 - 63

[2] He Shi production, etc. SME mobile internet marketing development status and countermeasures [J]. Computer Knowledge and Technology, 2015,11 (19): 206 - 208

[3] Ji Yongwei. SMEs mobile marketing problems and countermeasures [J]. Enterprise Herald, 2013 (16): 35 - 36

[4] Ai media consulting. 2015 China mobile marketing value and trend report [R]. Guangdong: Ai Media Consulting Group, 2015.

[5] Guo Hongjie. Enterprise marketing innovation strategy under the new situation [J]. Modern economic information, 2014, (12): 87-88 